\section{Un breve panorama del mundo editorial latinoamericano}

Gonzalo Arturo

Córdoba-Saavedra

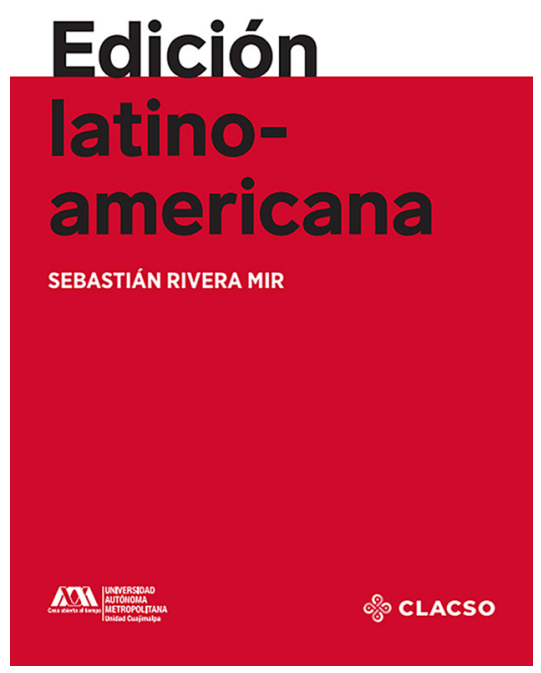

Sebastián Rivera Mir, Edición latinoamericana, ISBN: 978-987-722830-4, Ciudad Autónoma de Buenos Aires/México, CLACSO/UAM, 2021, 102 pp.
E 1 Consejo Latinoamericano de Ciencias Sociales (CLACSO) lanzó en abril de 2021 dos títulos de una nueva colección de divulgación científica: Políticas del cuidado, de Karina Batthyány, y Edición latinoamericana, de Sebastián Rivera Mir. De este último nos ocuparemos en las siguientes páginas.

Rivera Mir es doctor en Historia y ha publicado libros y artículos sobre la cultura de izquierda latinoamericana y sus prácticas (sobre todo, editoriales). En consonancia con esa línea de investigación se encuentra Edición latinoamericana, un breve pero completo panorama actual acerca de la industria editorial en esta parte del continente. Con el fin de proponer una lectura amena y simple, acorde con la intención divulgativa de la colección, la obra se estructura en diez apartados o capítulos que pueden leerse de manera independiente sin necesidad de acceder a ellos de manera lineal. Estos capítulos se titulan de la siguiente manera: "Ecosistema”, "Políticas", "Usos”, "Género", "Memoria”, "Editoriales", "Independientes", "Librerías", "Redes", "Lectores" y "Referencias". Veremos a continuación un breve resumen de cada uno. Dos razones explican el hacerlo de esta manera: la diversidad de temáticas y la relativa independencia de cada unidad o sección.

En "Ecosistema", el autor pone el foco en los actores del mundo editorial y en las circunstancias actuales: "No se trata simplemente de reproducir la llamada cadena productiva (autor-editor-distribuidor-librero-lector), sino también de comprender cómo estos sujetos se relacionan entre sí, mediante qué instituciones o mediadores y en el marco de qué conjunto de regulaciones" (18). ${ }^{1}$ Entender como un ecosistema el mundo editorial supone percibir las interrelaciones e interdependencia de todos los actores involucrados, advertir que existen diversas prácticas asociadas y que determinadas decisiones pueden provocar cambios en toda la cadena editorial, de la misma manera que dentro del mundo biológico todas las especies conviven en equilibrio.

El capítulo "Políticas" pone el foco en diversas experiencias gubernamentales llevadas a cabo en Latinoamérica en las últimas décadas, hecho que desmiente aquella sentencia común según la cual 'las políticas sobre el libro son inexistentes'. La realidad nos indica que sí hay múltiples legislaciones sobre el ecosistema editorial, pero que no logran abarcar al

1 Todas las citas pertenecientes a Edición latinoamericana corresponden a Rivera Mir, 2021, por lo cual sólo se nota el número de página. 
conjunto de los actores involucrados, es decir, son específicas para diversas áreas (por ejemplo, librerías, imprentas, editoriales). Frente a este panorama cabe destacar iniciativas como la creación del Instituto Nacional del Libro en Argentina, llevada al Congreso durante 2020 y en la que tienen voz representantes de toda la cadena.

El siguiente capítulo se titula "Usos" y en él Rivera Mir habla del libro como objeto portador de cultura en la región. El autor remarca que, desde mediados del siglo XIX, el libro:
se articuló como un mecanismo que potenciaba los tres pilares fun- damentales de los movimientos políticos progresistas: la educación, la reivindicación del trabajo manual (o artesanal) y las necesidades de difusión. Bajo esta triple articulación se desarrollaron distintos 'usos' por parte de los actores políticos y culturales (33).

También se hace hincapié en el uso social del libro como constructor de la memoria colectiva de un pueblo y se hace un repaso breve por sus posibilidades como objeto de disputa cultural.

El cuarto capítulo, "Género", parte de una afirmación contundente: a pesar de que el espacio editorial latinoamericano es marcadamente femenino, los puestos de poder suelen ser ocupados por varones. Sin embargo, existen diversas experiencias en cuanto a la edición y la exposición (o circulación) de libros que intentar paliar este problema, como la Feria del Libro Feminista (Argentina), LILA (Chile) o la Feria Nacional del Libro de Escritoras Mexicanas (FENALEM). Así, es posible pensar al libro como un artefacto de disputa política, un instrumento de pedagogía feminista. A su vez, esto impacta fuertemente en la bibliodiversidad regional y ha dado lugar a determinados actos de apropiación cultural por parte de las grandes industrias editoriales. De acuerdo con Rivera Mir, uno de los desafíos actuales consiste en preguntarnos "cómo se han establecido las distintas jerarquías y cómo estas construcciones han impactado en las diferentes actividades relacionadas con la edición" (46).

En "Memoria", el autor aborda las nociones asociadas al libro como espacio en el que se construye la memoria colectiva de las comunidades. En este sentido, fue considerado un elemento peligroso y de adoctrinamiento por parte de los diversos regímenes dictatoriales de la región, duramente combatido y señalado como 'subversivo'. Otro aspecto que el autor destaca es que la bibliodiversidad de nuestros pueblos se construye con una multiplicidad de soportes, principalmente resguardados en bibliotecas y archivos. Estos 'sitios de la memoria' han adquirido un nuevo sentido en las últimas décadas y se están desarrollando valiosas tareas para conservar dicho acervo cultural. 
El sexto capítulo de la obra se centra en las editoriales. El impacto de la Guerra Civil española en el espacio de la edición latinoamericana fue fuerte y resonante, tanto por la cantidad de migrantes españoles que llegaron a nuestro continente con el oficio a cuestas como por la caída de las importaciones de libros desde la península ibérica. Este hecho y la creación y proliferación de las editoriales universitarias (alrededor de la década de 1950) dieron forma en gran medida al mercado editorial latinoamericano tal como lo conocemos. Durante las últimas décadas del siglo XX muchas de las casas editoras más importantes pasaron a formar parte de los grandes conglomerados mundiales, a tal punto que hoy el $10 \%$ de las editoriales controla el 60 \% de la oferta de libros en la región.

El siguiente capítulo, una especie de complemento del anterior, se titula "Independientes". En la actualidad, este concepto está asociado a gran parte de la cadena del libro, así, encontramos autores independientes, pero también editoriales, librerías, distribuidoras, ferias: "El concepto es evasivo y suele definirse por negación. Los independientes son los que no forman parte de un conglomerado transnacional, los que no dependen del Estado, los que no reciben recursos de alguna universidad, entre otras posibilidades" (67). El abanico de actores independientes es cada vez mayor en una región en la que el trabajo editorial se vincula también con la autogestión y con los proyectos productivos a pequeña escala, comunitarios, barriales.

A continuación, el autor aborda la problemática asociada a las librerías. Ese espacio mítico elaborado y reelaborado en una gran cantidad de relatos es un "lugar simbólico, depositario de la cultura" (75). Sin embargo, esta profusión de evocaciones literarias no se condice con la cantidad de estudios serios dedicados al sector, caso contrario al de las editoriales, las políticas públicas o las bibliotecas. La figura del librero asume en ocasiones la función de mediador entre autores y lectores, a la manera de un gestor cultural siempre relacionado con la comunidad en la que se asienta, e históricamente encontramos gran cantidad de casos de libreros-editores.

El penúltimo capítulo apunta a la construcción de redes. El autor entiende que el libro es el resultado del esfuerzo conjunto de una serie de actores diversos, situado en la convergencia de trabajos asociados, "es principalmente un producto transfronterizo" (83), que rebasa límites de tipo físico y simbólico. Y aquí hay que reconocer un hecho paradójico: mientras que los procesos de derecha o militaristas en la región lucharon contra el libro como objeto portador de ideas y contra los hacedores culturales, el exilio de los intelectuales propició la construcción y consolidación de redes 
transfronterizas, lo cual ha ayudado a afianzar los lazos entre los países latinoamericanos.

Finalmente, Rivera Mir se preocupa del último eslabón en la cadena del libro: los lectores. La lectura es entendida como una actividad cultural que permite la formación de un pensamiento crítico y se relaciona principalmente con dos espacios que persiguen objetivos particulares: la escuela, cuyo fin es formar competencias lectoras, y la biblioteca, que en su afán por diferenciarse de aquella puede asociarse con lo lúdico. Se debe erradicar la idea de que existe una manera correcta de leer y reconocer la multiplicidad de prácticas relacionadas con esta actividad, los espacios en los que se desarrolla, el tipo de lecturas elegidas y el soporte en el que se lee. Hay que hacer hincapié, además, en que la lectura es un derecho y en este sentido todas las iniciativas enfocadas a democratizar el acceso a los libros son vitales para el fortalecimiento de la región.

En términos generales, el libro cumple satisfactoriamente con su objetivo de ser un texto de divulgación científica acerca de un tema siempre actual y desde una perspectiva amplia. Rivera Mir acompaña cada capítulo o entrada con una serie de ejemplos muy variada, en la que encontramos casos de casi todos los países latinoamericanos y referencias a una gran cantidad de estudios específicos que podemos consultar en el apartado de referencias bibliográficas, lo cual da cuenta de que, más allá del lenguaje llano con el que el autor escribe, el texto se encuentra debidamente actualizado. Aquellos lectores especializados en asuntos relacionados con la edición probablemente no encuentren novedades en esta obra, puesto que su mirada es, si bien completa, poco profunda. Sin embargo, se debe destacar que esta iniciativa se encuentra dentro de una colección de acceso abierto y constituye, sin lugar a dudas, una buena manera de acceder a los principales núcleos de sentido relacionados con el quehacer editorial y lector desde una perspectiva latinoamericana y crítica. La intención del autor ha sido ofrecer una descripción de la diversidad de problemáticas vinculadas con la cadena del libro y proponer una revisión de los debates actuales vinculados con el quehacer editorial. El texto completo puede descargarse de manera gratuita desde la página de CLACSO. ${ }^{2}$

2 El libro puede consultarse en el siguiente link: http:/biblioteca.clacso.edu.ar/clacso/ se/20210406023112/Edicion-latino.pdf 


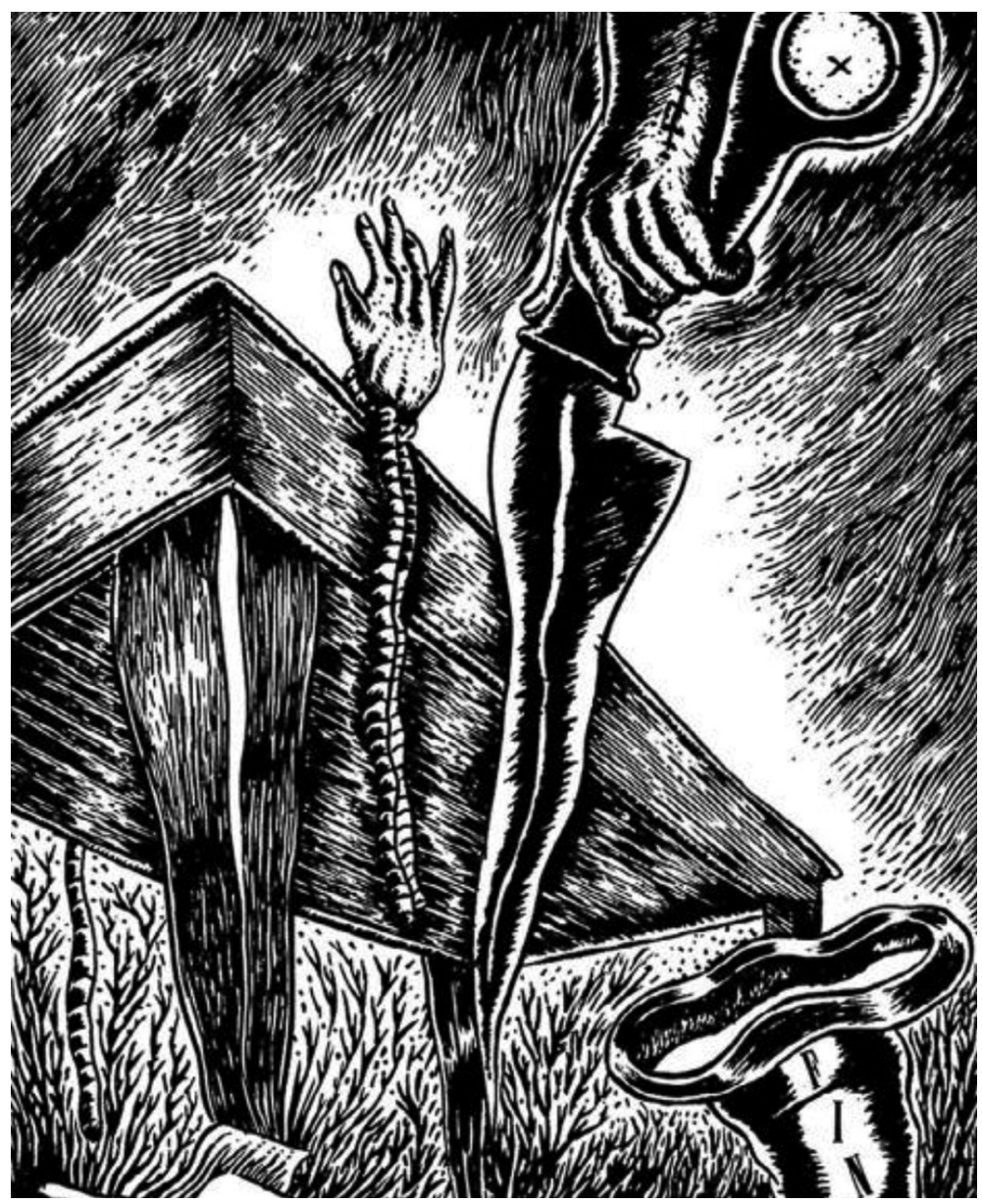

Viñeta de adaptación de El matadero, Suplemento Grueso Picado de la revista Fierro (2006). Tinta con Pluma y pincel : Juan Soto.

Prohibida su reproducción en obras derivadas. 